\title{
LEARNING FROM THE HISTORIC CITY: ARCHITECTURAL HERITAGE REHABILITATION AND GIS, THE URS-VISEU NOVO (PORTUGAL) LEGACY
}

\author{
A. M.T. Martins ${ }^{1}$, J. Gonçalves ${ }^{2}$, B. Santos ${ }^{3}$, S. Marques ${ }^{4}$ \\ ${ }^{1}$ University of Beira Interior, Lab2PT, CIDEHUS (PORTUGAL) \\ ${ }^{2}$ University of Beira Interior, CITTA (PORTUGAL) \\ ${ }^{3}$ University of Beira Interior, CERIS-CESUR (PORTUGAL) \\ ${ }^{4}$ University of Beira Interior (PORTUGAL)
}

\begin{abstract}
All cities share a similar challenge: "How to rehabilitate the historic centre without denigrating its identity and at the same time encourage private investment in built cultural heritage in order to avoid its degradation?" The historic centres are the oldest and most central areas of the cities, defining their identity, but have fallen into economic, social and residential decay, in part by the abandonment and aging of their most outstanding buildings.

The presented paper intends to study the projects promoted by the Portuguese Municipality of Viseu, namely through the Urban Rehabilitation Society Viseu Novo, in short URS Viseu Novo. This revitalization strategy of the Historic Centre of Viseu aims to identify the buildings' most relevant problems, the rehabilitation's proposed objectives and the feasible solutions to renovate them promoting youth housing, cultural events and others.

A contextualization analysis of the URS's work in the historic area of Viseu is presented through the inventory of its interventions using Geographic Information Systems (GIS). GIS spatial analyses, syntheses and conclusions can be used for the presentation of rehabilitation solutions duly framed in the goals and environment intended for these noble areas. As a result of this work, and starting from this principle, another research is being developed and serves as theme for the Integrated Master in Architecture Dissertations, highlighting the relevance and pertinence of this theme.
\end{abstract}

Keywords: Architectural Heritage, Architectonic and Urban Rehabilitation, Inventories, GIS.

\section{INTRODUCTION}

The cultural heritage is the symbolic synthesis of the identity values of a society that recognizes them as their own. The Heritage is an exceptional document of historical memory and, therefore, key in the construction capacity of culture, insofar as it allows to cumulatively verify the attitudes, behaviours and implicit or adjudicated values of cultural production over time [1].

With the expansion of cities, and at a time in which the periphery begins to reach significance, comes the time of reordering. This is, a time to allow a new development with a new emerging perspective, a culture of retrofitting and rehabilitation, in short, the transformation of existing built historic buildings and heritage [2] [3].

According to Martins, Pérez Cano and Mosquera Adell [2], the city is a place of meeting and reunion, in which various interests and elements interact. These interests are economic, cultural or even ideal, and they allow, through the remaining architectural heritage, to provide for the contemporary city a possible and positive response to the demands of the contemporary age, might they be physical, social or cultural [3].

The historic centres are the oldest and central areas of the cities, constituting their identity, but have fallen into economic, social and residential decay, in part by the abandonment and aging of their most outstanding buildings.

The knowledge and the use of heritage are, currently, essential elements for their safeguarding, sustainability and evaluation as well as factors of progress in various aspects of development, in particular, when underlining the interdependence between culture and community life quality [2] [4]. According to Mine [5] it is necessary to provide contemporary uses to protect the historical heritage and transfer this attitude and new life to these buildings to carry them to the future generations. 
As Capitel [6] says, projecting on existing architecture becomes reflective and eclectic, in search of the suitability for specific purposes, relating to the original building. The problem of continuity or figurative discontinuity, between the new and the old, loses its most superficial interpretation to become a diverse compositional tool [3] [4]. As a result, the link between the old and the new translates into the "memory" of the new which is simultaneously a dialectical link between the past and the future that is embodied in the present.

The transformation of historic buildings and its consequent adaptation to contemporary living needs are nowadays one of the major concerns in the field of the construction of the contemporary city [2] [4].

All cities share a similar challenge: "How to rehabilitate the historic centre without denigrating its identity and at the same time encouraging private investment in built cultural heritage in order to avoid its degradation?" In fact, architectural heritage and the historical centre are a legacy which must be considered when rehabilitating the historic centre of Viseu.

The presented paper intends to study the projects promoted by the Portuguese Municipality of Viseu, namely through the Urban Rehabilitation Society Viseu Novo (URS-Viseu Novo). This revitalization strategy of the Historic Centre of Viseu aims to identify the buildings most relevant problems, the rehabilitation's proposed objectives and the feasible solutions.

The paper is organized as follows: Section 2 presents a literature review considering the importance of research in Architecture using GIS. Section 3 presents a reflection about the architectural heritage rehabilitation and GIS applied to a specific case study: the URS-Viseu Novo (Portugal) experience. A methodology and proof of concept was achieved, regarding this experience, and one of the outputs was a master dissertation in Architecture [7]. Section 4 concludes the paper highlighting some reflections of the authors on the URS-Viseu Novo legacy.

\section{LITERATURE REVIEW}

When considering Architecture, GIS was initially used for urban development before being extended to urban planning and management [8]. Today GIS encompass the various scales of matter and space, offering powerful tools for the analysis, design, production and management of architecture. As Pinto Puerto et al. [8] state, it is used in different ways to understand architecture in all its complexity connecting it to the cultural, social and historical aspects of a spatial environment highlighting the usefulness and vast potential of GIS for analysing and managing heritage in a multi-disciplinary yet coherent vision.

Decay of city centres and their loss of housing functions are one of the most important problems of European historical cities. The solution to these problems can be addressed through a careful rehabilitation of degraded city centres areas. In the opinion of Navas Carrillo et al. [9], GIS facilitate and accelerate access to information, helping heritage professionals taking fast and accurate decisions about protection or conservation issues. Such systems can manage a vast amount of data and information from several sources, continuous monitoring and spatial analyses that can support the identification of areas where rehabilitation is essential.

Furthermore, a wide range of architectural heritage spatial studies depend on multi-criteria analyses to simplify otherwise complex spatial studies [10]. These types of analysis, overlaying different characterizing spatial variables, are at the core of geoprocessing GIS procedures. In this sense, GIS offers architects more than just base maps and site diagrams, allowing them to make informed decisions based on the analysis of real world data [11].

Ferreira Lopes et al. [12] and Pinto Puerto [13] present several applications of GIS in the field of cultural heritage that can be applied to historical city centre rehabilitation strategies: support in the creation of a heritage inventory; discover patterns on spatial, physical and temporal characteristics to determine future actions in heritage asset management; development of control and prediction for heritage conservation; aiding in the definition of strategic plans for natural and/or cultural heritage management; and the dissemination of information.

Despite all the advantages mentioned, architects adopting GIS techniques, either in practice or research, are still scarce and most of architecture curricula have little or no GIS contents [8] [11]. Monsur et al. [11] state that the few Architecture curricula with GIS courses, lack the conceptual connection with traditional architectural subjects. 
However, recent examples of the development of GIS models and tools to aid the decision-making process associated with intervention in architectural heritage, in its various applications, can be found mainly at the research level. Applications in built heritage and energy efficiency [14] [15], cultural heritage management (e.g. castles, ecclesiastical heritage) [16] [17], traditional rural buildings [18], contemporary heritage [19] or city heritage management [7] [20] [21] [22], can be found in the literature.

With regard to architecture curricula, in the last two decades there has been an increase in the integration of digital technologies throughout the training of thinking and making of space, both in dedicated curricular units such as Computer-Aided Design (CAD) and Geographical Information System (GIS), or in cooperation with later year units, including the final dissertation / project [23]. According to Kara [24], the various technologies of computing aided drafting, enumerating, modelling, and analysis started to shape the overall curricular structure of architectural education and need to be implemented as support courses in order to compensate the learning curve and the number of software available to architects.

The incorporation of GIS in the teaching-learning process is thus in line with the demand for more transversal and integrative formations between architecture disciplines. Its application to heritage opens up new approaches to teach and research into architectural heritage rehabilitation.

\section{ARCHITECTURAL HERITAGE REHABILITATION AND GIS, THE URS-VISEU NOVO (PORTUGAL) LEGACY}

The concept of Urban Rehabilitation is described in its legal regime [25] as a form of integrated intervention on the existing urban fabric, in which urban and architectural heritage is maintained, in whole or in part, and modernized by carrying out remodelling works or improvement of urban infrastructures, equipment and urban or green spaces for collective use and construction, reconstruction, expansion, alteration, conservation or demolition of buildings.

According to Mouraz [26], urban rehabilitation has become an integrated process, prompting principles that promote the use of innovative solutions, sustainable and compatible with the heritage preservation of historical buildings, solving pathologies and ensuring, in parallel, the framework of the building with its surroundings.

'Urban rehabilitation area' [27] means a territorially delimited area which, due to the insufficiency, degradation or obsolescence of buildings, infrastructures, equipment for collective use as well as urban and green spaces of collective use, regarding their conditions of use, solidity, safety, aesthetics or salubrity, justify an integrated intervention, through an urban rehabilitation operation approved in its own legal instrument or in a detailed urban rehabilitation plan.

However, conservation is the set of preventive and safeguard actions aimed at ensuring an unlimited duration of the object's material configuration [28]. As Torsello [4] tells us, the opposition between old and new, conservation and innovation, is the very nature of the intervention, namely its constant and renewed historic condition [2].

According to Alaix and Werner [29] assessments on heritage and contemporary society should be emphasized according to three values: (a) Identity value in which heritage can act as an image generator and territorial identity; (b) Economic value regarding the added value of the assets which can generate new business opportunities and, therefore, become a source of employment and a new source of income for the territory; (c) Social value while considering it as the development of a project to increase the value of heritage that can contribute to improve the population's quality of life.

\subsection{GIS applied to a specific case study}

\subsubsection{The Integrated master degree in architecture at UBI and the dissertation / project}

The Bologna Declaration introduced changes in Portuguese universities which required a reorganization of Architectural programs in Architecture Schools. The University of Beira Interior (UBI), in Covilhã, was one of these universities [23] [30].

The integrated master in architecture is a 5 -year program which combines undergraduate (1st cycle) and postgraduate (2nd cycle) studies into a single course of 300 ECTS (European credit transfer system) [23] [31]. The $1^{\text {st }}$ cycle enables students to obtain a Bachelor degree in basic Architecture sciences after the completion of 6 semesters (180 ECTS). The $2^{\text {nd }}$ cycle, which provides students with a master degree in Architecture, comprises 3 semesters of curricular units (90 ECTS) and one semester 
entirely dedicated to the Dissertation/Project (30 ECTS). The curricular unit Dissertation/Project can be practical (Architectural Project) or theoretical (Dissertation) [23] [31] [32] [33].

In the UBI master degree in Architecture, the basis of architectural knowledge is achieved not only by technical curricular units but also by a history and a theoretical course intertwined with the Project curricular units [23] [32]. The interdisciplinarity and interrelation, which link both research and education, are the basis for the production of knowledge at the UBI Department of Civil Engineering and Architecture [31].

Among the different research themes, a particular attention is devoted to the built heritage in Portugal, and its connection with the engineering sciences as thermal comfort, acoustics, daylighting and more recently its connection with the Geographical Information Systems as a way of spatial analysis and project decision [23]. The future of built heritage conservation is focused on the sustainable built environment [31].

Conservation does not require buildings to be preserved in their original condition to accept contemporary use. It may change over time as community values evolve. However it is important as a cultural asset, to retain its original heritage features [31]. While heritage conservation is a key player in sustainability planning, interdisciplinary skills are needed to deliver the heritage studies and projects of the new generation architects, combining aspects of cultural heritage with the best preventive conservation, projects, methodologies and practices [31].

\subsubsection{The URS - Viseu Novo}

In Portugal, the historic centres have a great diversity of construction types of different ages with different heritage values. Intervention in historic centres has become one of the priorities of municipalities. Rehabilitation of buildings and public spaces is fundamental in order to attract new inhabitants and encourage tourism [7].

With the advent of the crisis in Portugal, many areas have fallen into decay and architecture was no exception. The lack of new construction and expecting spaces affected the construction market, forcing a reflection on this theme. Due to the absence of spaces in the Portuguese cities for new construction, the study of strategies that involve heritage and ancient buildings became crucial [7].

According to Luque [34], the way in which Historic City and community relate has a context: the Municipality. However, the Municipality is something more than the place of encounter and significance where the City becomes historic, and where the individual coexists with his past. The local institution becomes key in the continuity of the relationship between Heritage and society, and how it can contribute to generate positive responses to heritage protection and safeguarding.

The city of Viseu, is a middle-sized city and capital of district with an important and significant historic centre that is assumed as a reference heritage within its region [35]. Public and private entities are both involved in the management of built heritage. The historical centre has always been a prominent area within the Municipal Master Plan (PDM) of Viseu [35].

In addition to these urban planning measures, legal, financial and administrative support was added as a complement to the creation of a Local Technical Office for the Historic Centre (GTL- Gabinete Técnico Local), culminating in the creation of an Urban Rehabilitation Society (URS) Viseu Novo. The municipality also promoted the definition of a Critical Urban Reconversion and Recovery Area, which covers the most important area of this centre [35].

In 2005, the Urban Rehabilitation Society of Viseu - URS Viseu Novo - was created. The social capital was subscribed by the City Council of Viseu (55\%) and by the Institute of Housing and Urban Rehabilitation (45\%). However, in 2015 the municipality of Viseu had full financial responsibility for URS Viseu Novo [7]. This URS only started activity in 2006, directing the urban rehabilitation process of Critical Urban Reconversion and Recovery Area of Viseu with the objective of promoting the social, physical and economic revitalization of the Historic Centre, Cava de Viriato, Bairro Municipal and the Ribeira Zone [7].

The URS - Viseu novo, until now, has intervened in seventeen buildings inserted in the historic centre of Viseu as shown in the URS' webpage [36].

\subsubsection{Methodology and proof of concept}

The following steps were established in the problem-based project methodological approach adopted in a master's dissertation for the development of a useful GIS for Viseu architectural heritage rehabilitation. 
Since the buildings considered in the study were the ones contemplated in URS-Viseu Novo, the initial step comprises the collection of information. For general applications it will be necessary to consider, in addition to the steps listed, an initial step for identifying buildings with heritage architectural interest.

Methodological steps:

a) Online and field data collection (from URS-Viseu Novo website [36]): area of intervention; historical centre boundary; identification, location and characteristics of buildings; type of intervention (rehabilitation, restoration, reconversion, reconstruction, conservation, maintenance and retrofitting, among others); intervention project (framework, project phases and drawings); photos.

b) Location of the buildings on a digital cartographic map support. The GIS program ArcGIS $₫$ 10.5.1 was used and the European Terrestrial Reference System 1989 (ETRS89) was considered.

c) Inventory of URS-Viseu Novo buildings and creation of identification files. In this step the information gathered online and in the field were organized and processed as digital files to make the consultation and management of the architectural heritage information easier. An ID was assigned to each building to link the alphanumeric information organized into tables, images and drawings to the building graphical information.

d) Centralization of documentation in a Database. A relational database was created and administrated in Microsoft Excel $\circledast$ and ArcGis ${ }^{\circledR}$ was used for linking the database, graphical information, photos and drawings in a same computer program (Figure 1). Besides the great advantage of allowing to connect all these types of information, ArcGis $®$ is a program that enables to perform spatial analysis (Figures 2 and 3 ), the management of large datasets, and the presentation of information in a map/graphical form.

The next step to be developed in a future master's dissertation, is the evolution of the GIS tool to assess the rehabilitation potential of buildings based on their current condition and architectural heritage interest.

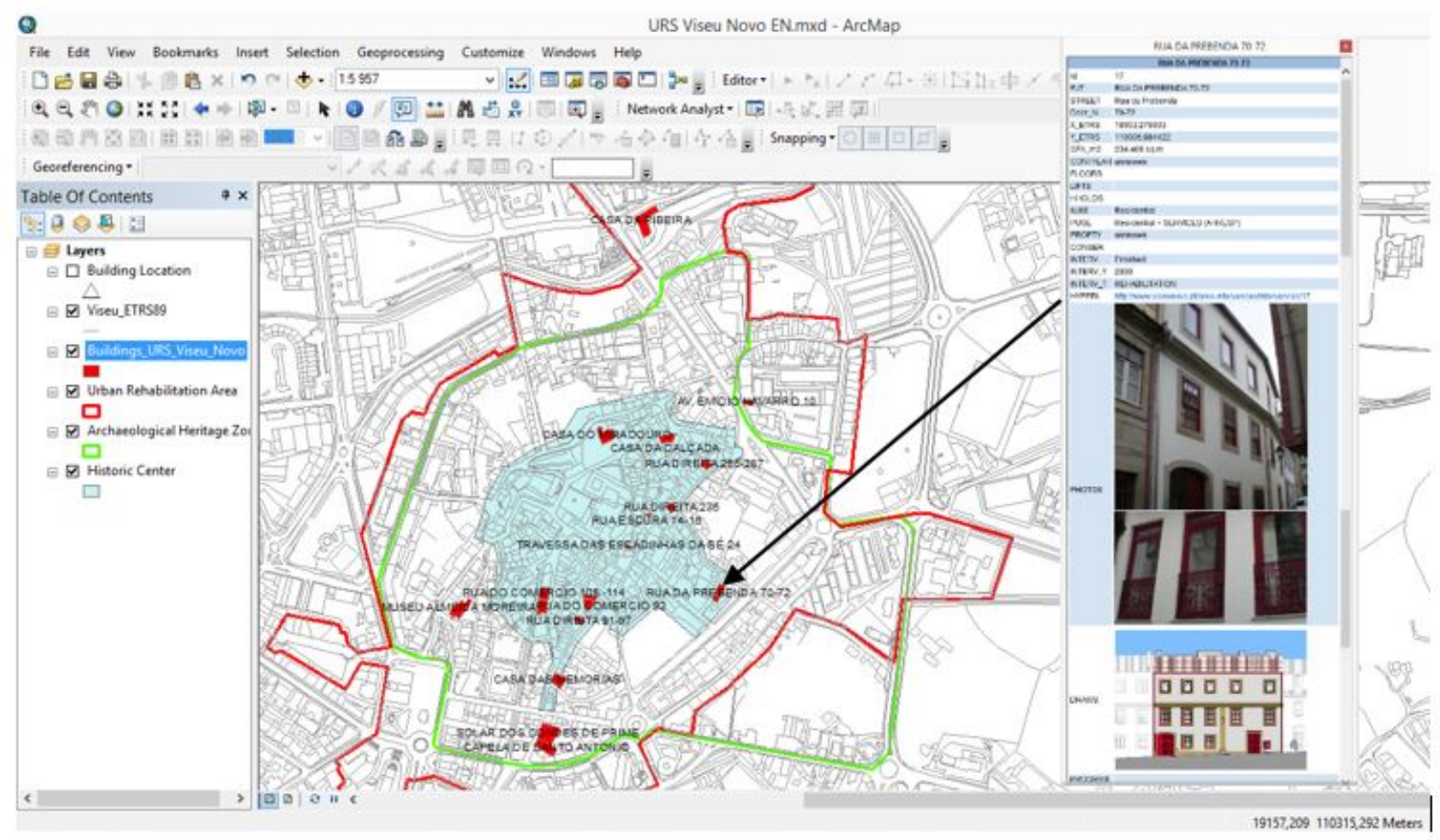

Figure 1. URS Viseu Novo GIS model: building data query. 

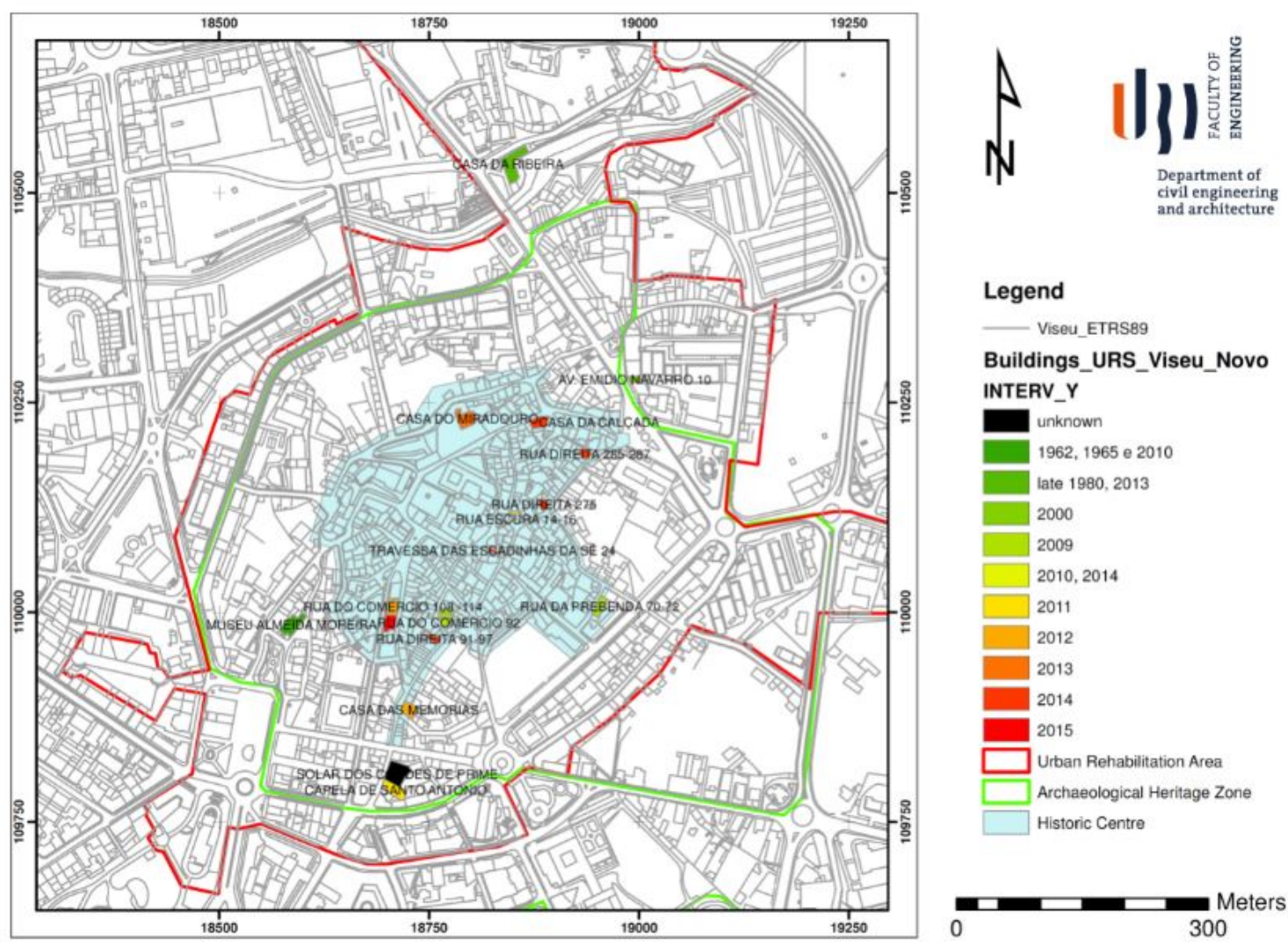

Legend

- Viseu_ETRSB9

Buildings_URS_Viseu_Novo INTERV_Y

unknown

1962,1965 e 2010

late 1980,2013

2000

2009

2010, 2014

2011

2012

2013

2014

2015

Urban Rehabilitation Area Archaeological Heritage Zone Historic Centre

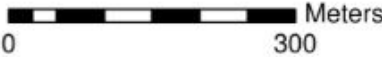

Figure 2. Thematic map: Spatial distribution by year of intervention.
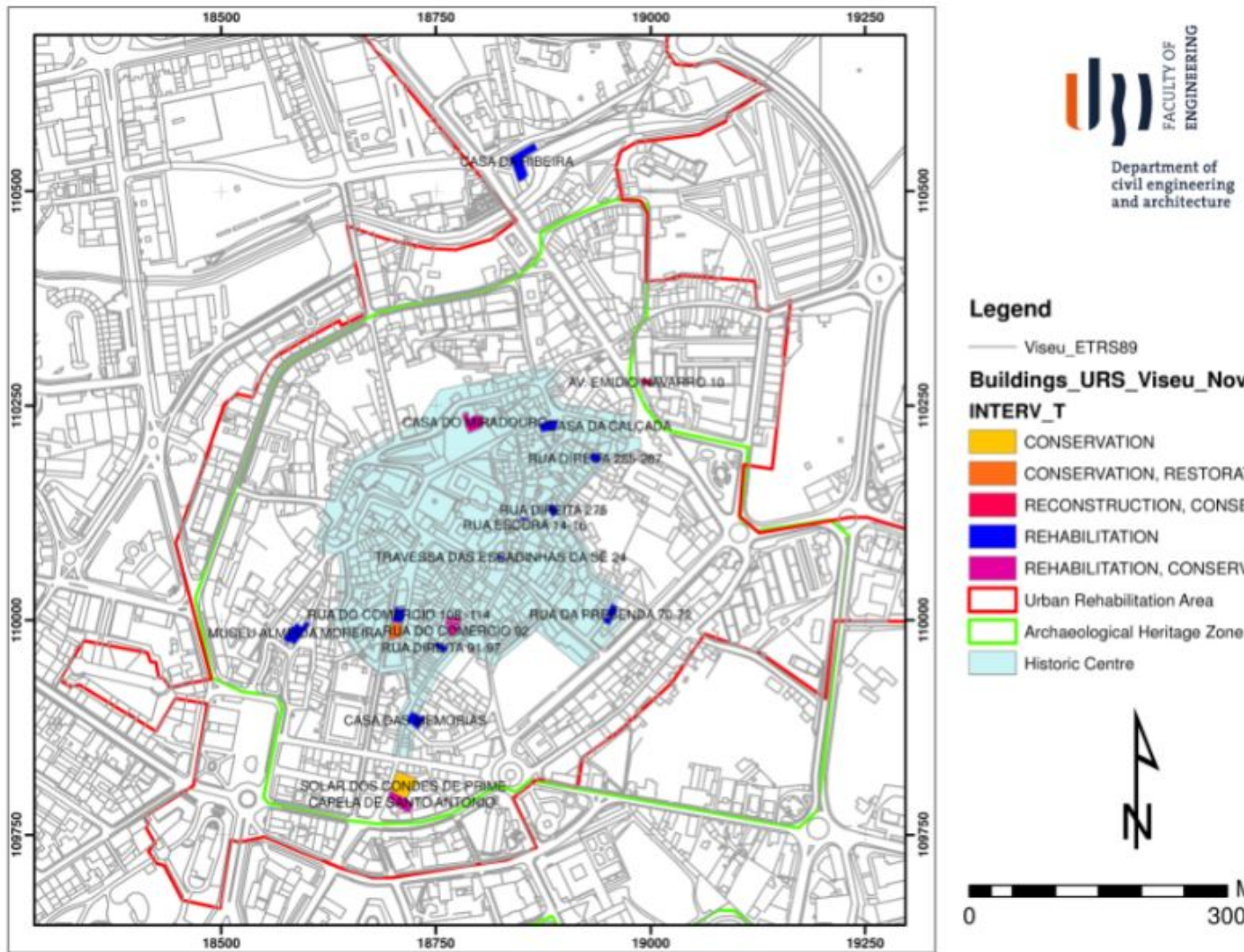

\section{Legend}

- Viseu ETRSB9

Buildings_URS_Viseu_Novo

INTERV_T

CONSERVATION

CONSERVATION, RESTORATION

RECONSTRUCTION, CONSERVATION

REHABILITATION

REHABILITATION. CONSERVATION

$\square$ Urban Rehabilitation Area

Archaeological Heritage Zone

Historic Centre

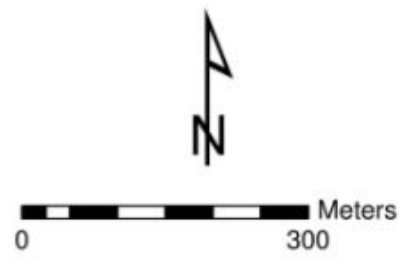

Figure 3. Thematic map: Spatial distribution by type of intervention. 
The methodological approach can be schematically represented as shown in Figure 4.

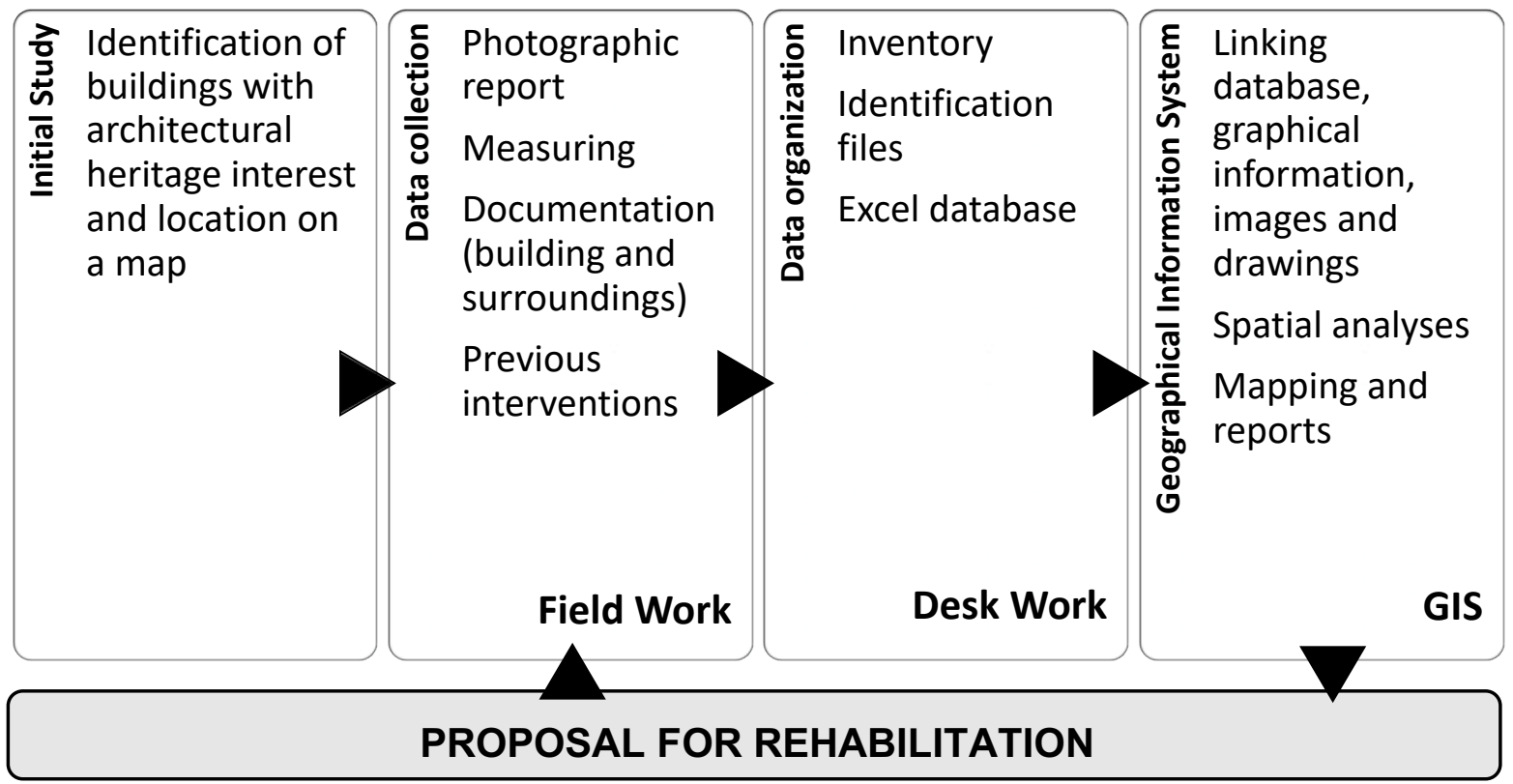

Figure 4. Diagram of a GIS development as a tool to support architectural heritage rehabilitation.

\section{CONCLUSIONS}

Within the framework of a final dissertation work, a computer-aided approach using GIS was developed. This dissertation tackles the analysis of the historic centre of Viseu (Portugal), with particular focus on the analysis of the work done by heritage management and rehabilitation entity "Viseu Novo, SRU", using GIS for inventory allowing for syntheses and conclusions. This approach can be used for systematic monitoring of spatial conditions and can evolve to an evaluation tool of historic city centres, evidencing priority areas for rehabilitation.

This work served as proof of concept, since it demonstrated that with a duly organized database, the definition of a built heritage management system is feasible using GIS.

In fact, the historic city centre of Viseu is a prolific field of research in historic buildings and heritage and the work done by the URS is achieved by good practices based on previous successful experiences and a legacy for future ones, either academic or professional.

As a final remark, it is possible to conclude that the use of GIS in architecture education is a major asset, a useful tool for research and a resource for design options definition in rehabilitation of the built heritage.

\section{ACKNOWLEDGEMENTS}

The authors acknowledge University of Beira Interior, Lab2PT - Landscapes, Heritage and Territory laboratory (AUR/04509), CIDEHUS - Interdisciplinary Centre for History, Cultures and Societies (HIS/00057), CIAUD - Research Centre for Architecture, Urban Planning and Design (EAT/04008), CITTA - Research Centre for Territory, Transports and Environment (Multi/04427) and CERIS-CESURCivil Engineering Research and Innovation for Sustainability (ECl/04625).

The authors thank CITTA (Multi/04427) for the financial support on this work.

\section{REFERENCES}

[1] M. Martín, "Sobre el necesario vínculo entre el patrimonio y la sociedad. Reflexiones críticas sobre la Interpretación del Patrimonio," Estud. Património, vol. 1, pp. 25-37, 2001.

[2] A. M. T. Martins, M. T. Pérez-Cano, and E. Mosquera-Adell, "Monastic Buildings: A Review About New Uses on Former Monasteries. The Portuguese Cistercian Case," IOP Conf. Ser. Mater. Sci. Eng., vol. 471, no. (in press), 2019. 
[3] A. M. T. Martins and J. S. Carlos, "The re-use(s) of a Cistercian Monastery in Lisbon," ACEE - J. Archit. / Civ. Eng. / Environ., vol. 6, no. 4, pp. 45-60, 2013.

[4] B. P. Torsello, "Project, conservation, innovation," Loggia, vol. 8, pp. 10-17, 1986.

[5] T. Z. Mine, "Adaptive re-use of monuments: restoring religious buildings with different uses," J. Cult. Herit., vol. 14, no. 3, pp. S14-S19, 2013.

[6] A. Capitel, Metamorphosis of monuments and theories of restoration. Madrid: Alianza Editorial, 1999.

[7] S. R. N. Marques, "Centro Histórico de Viseu, Viseu Novo, SRU: Proposta de Reabilitação para Hostel," Universidade da Beira Interior, 2018.

[8] F. Pinto Puerto, R. Angulo Fornos, M. Castellano Román, J. Alba Dorado, and P. Ferreira Lopes, "Using BIM and GIS to Research and Teach Architecture," in Architectural Draughtsmanship, 2018.

[9] D. Navas-Carrillo, B. Del Espino Hidalgo, F. J. Navarro-De Pablos, and M. T. Pérez Cano, "The urban heritage characterization using 3D geographic information systems. The system of mediumsized cities in Andalusia," Int. Arch. Photogramm. Remote Sens. Spat. Inf. Sci. - ISPRS Arch., vol. 42, no. 4/W10, pp. 127-134, 2018.

[10] G. J. de M. Freire, "Reinserimento degli spazi urbani di insediamenti precari (favelas) mediante il GIS," Disegnarecon, vol. 6, no. 11, pp. 71-80, Mar. 2013.

[11] M. Monsur and M. Zakiul Islam, "GIS for Architects: Exploring the Potentials of Incorporating GIS in Architecture Curriculum," in ARCC Conference Repository, 2014.

[12] P. Ferreira-Lopes and F. Pinto-Puerto, "GIS and graph models for social, temporal and spatial digital analysis in heritage: The case-study of ancient Kingdom of Seville Late Gothic production," Digit. Appl. Archaeol. Cult. Herit., 2018.

[13] F. Pinto, M. Castellano, R. Angulo, and J. Dorado, "El uso del BIM y del SIG en la enseñanza e investigación de la la Arquitectura," in EGA Revista de Expression Grafica Arquitectonica, no. January, 2016, pp. 507-514.

[14] P. Caputo and G. Pasetti, "GIS tools towards a renovation of the building heritage," in Energy Procedia, 2017.

[15] K. Fabbri, M. Zuppiroli, and K. Ambrogio, "Heritage buildings and energy performance: Mapping with GIS tools," Energy Build., vol. 48, pp. 137-145, 2012.

[16] A. Oppio, M. Bottero, V. Ferretti, U. Fratesi, D. Ponzini, and V. Pracchi, "Giving space to multicriteria analysis for complex cultural heritage systems: The case of the castles in Valle D'Aosta Region, Italy," J. Cult. Herit., vol. 16, no. 6, pp. 779-789, 2015.

[17] P. Spiridon, A. Ursu, and I. Sandu, "Heritage Management using GIS," in 16th International Multidisciplinary Scientific GeoConference SGEM, 2016, pp. 263-270.

[18] M. Cano, E. Garzón, and P. J. Sánchez-Soto, "Historic preservation, GIS, \& rural development: The case of Almería province, Spain," Appl. Geogr., vol. 42, pp. 34-47, 2013.

[19] J. Rodríguez-Lora, "LA PROTECCIÓN DEL PATRIMONIO CONTEMPORÁNEO. Arquitectura en torno al Movimiento Moderno en Sevilla. Una revisión urbano-patrimonial tres décadas después," Universidad de Sevilla, 2018.

[20] V. Almeida, "Valores Urbanos e Património na definição de Princípios de Intervenção: o Centro Histórico de Viseu," Universidade de Coimbra, 2017.

[21] P. Chatzigrigoriou and E. Mavrikas, "Saving historic buildings with multi-criteria GIS tool: The case of Hermoupolis - Cyclades," Proc. Digit. 2013 - Fed. 19th Int'I VSMM, 10th Eurographics GCH, 2nd UNESCO Mem. World Conf. Plus Spec. Sess. fromCAA, Arqueol. 2.0 al., vol. 2, pp. 53-59, 2013.

[22] B. Husseini and Z. Bali, "Documentation, using GIS techniques in conservation of a World Heritage Site, a case study of 'the Old City of Jerusalem," Int. Arch. Photogramm. Remote Sens. Spat. Inf. Sci. - ISPRS Arch. 25th Int. CIPA Symp., vol. 40, no. 5W7, pp. 229-234, 2015.

[23] B. Santos, A. Martins, I. Campos, J. Gonçalves, and P. Almeida, "When Past and Future Meet in Architecture Teaching: Heritage and GIS," in ICERI 2018 - 11th annual International Conference of Education, 2018, no. November, pp. 902-910. 
[24] L. Kara, "A Critical Look at the Digital Technologies in Architectural Education: When, where, and how?," Procedia - Soc. Behav. Sci., vol. 176, pp. 526-530, 2015.

[25] "DR 9/2009 (2009-05-29)," Diário da República Eletrónico. [Online]. Available: https://data.dre.pt/eli/decregul/9/2009/05/29/p/dre/pt/html. [Accessed: 14-Jan-2019].

[26] C. P. Mouraz, "A Importância da Caracterização Construtiva e do Estado de Conservação na Sustentabilidade das Ações de Reabilitação: um caso de estudo no Centro Histórico de Viseu," Universidade de Coimbra, 2016.

[27] "Lei 32/2012 (2012-08-14)," Diário da República Eletrónico. [Online]. Available: https://dre.pt/pesquisa/-/search/175306/details/maximized. [Accessed: 14-Jan-2019].

[28] M. Justicia, Antología de textos sobre restauración. Universidade de Jaén, 1996.

[29] M. Alaix and J. Werner, "Patrimonio y Territorio: una reflexión sobre los proyectos de puesta en valor del patrimonio," Estud. Património, vol. 1, pp. 38-41, 2001.

[30] "Processo ACEF/0910/26421 do Ciclo de Estudos em Arquitectura," Covilhã, 2012.

[31] A. M. T. Martins, J. S. Carlos, and M. Nepomuceno, "BUILT HERITAGE RESEARCH AND EDUCATION," in 9th International Conference on Education and New Learning Technologies, 2017, pp. 10268-10277.

[32] A. M. T. Martins, "Curriculum Design: History of Portuguese Architecture and the Integrated Master Degree in Architecture," in 12th International Technology, Education and Development Conference, 2018, pp. 530-535.

[33] A. M. T. Martins, P. E. M. Carvalho, and A. B. Coelho, "2 ${ }^{\circ}$ Relatório de Follow-up ( $N^{\circ}$ de Processo ACEF/0910/26421) do Ciclo de Estudos em Arquitectura," Covilhã, 2015.

[34] M. S. Luque, "La gestión municipal del patrimonio cultural urbano en España," University of Málaga, 2005.

[35] "Guia para a reabilitação do Centro Histórico de Viseu." [Online]. Available: http://cmviseu.pt/guiareabcentrohistorico/capa/index.php. [Accessed: 14-Jan-2019].

[36] Viseu Novo SRU.” [Online]. Available: http://www.viseunovo.pt/. [Accessed: 10-Jan-2019]. 